\title{
Preparation and Properties of Clay/SEBS Intercalated Composites
}

\author{
Tomohiro YAMAGUCHI ${ }^{1, *}$ and Eisuke YAMADA ${ }^{2}$ \\ ${ }^{1}$ Aichi Industrial Technology Institute, Nishishinwari, Hitotsugi-cho, Kariya, Aichi 448-0003, Japan \\ ${ }^{2}$ Department of Applied Chemistry, Aichi Institute of Technology, \\ 1247 Yachigusa, Yakusa-cho, Toyota, Aichi 470-0392, Japan \\ *Corresponding author: tomohiro_yamaguchi@pref.aichi.lg.jp \\ Received October 29, 2005; Revised January 11, 2006; Accepted February 1, 2006 \\ (C) 2006 The Society of Rubber Industry, Japan
}

\begin{abstract}
Clay/polystyrene- $b$-poly(ethylene-co-butylene)- $b$-polystyrene triblock copolymer (SEBS) intercalated composites were prepared by melt-blending. The clays were a pristine montmorillonite (Mt) and three organically modified montmorillonites (organo-Mts) with different amounts of distearyldimethylammonium (D18) cation. The amounts of D18 were 50,70 and $100 \%$ of the cation exchange capacity (denoted as D18Mt(50), D18Mt(70) and D18Mt(100), respectively). The clay/SEBS composites were characterized by field-emission scanning electron microscopy (FE-SEM), X-ray diffraction analysis (XRD). The dynamic mechanical analysis (DMA) and the tensile properties were also examined.

The size of agglomerated clay particles decreased with the increasing amount of D18. The FE-SEM image of $\mathrm{D} 18 \mathrm{Mt}(100) / \mathrm{SEBS}$ revealed that the clay particles were dispersed at the sub- $\mu \mathrm{m}$ level $(100-500 \mathrm{~nm})$. The XRD patterns suggested that the SEBS chains were inserted into the interlayers of the organo-Mts. The DMA curves indicated that the addition of the organo-Mts produced an increase in the storage modulus in the rubbery plateau region, but a slight decrease in the glass transition temperature of the polystyrene domains. The tensile properties of the organo-Mt/SEBS composites were higher than those of the unmodified Mt/SEBS. D18Mt(100)/SEBS displayed an improved tensile modulus, tear strength and hardness compared to pure SEBS, without sacrificing the tensile strength and elongation at break.
\end{abstract}

Keywords Clay, Intercalation, Melt-blending, Montmorillonite, Nanocomposites, SEBS, Surface modification, Thermoplastic elastomers.

\section{Introduction}

In recent years, clay/polymer nanocomposites have attracted great interest by many researchers. Nanocomposites are defined by the particle size of the dispersed phase having at least one dimension less than $100 \mathrm{~nm}$. Due to their nanoscale features, they often exhibit physical properties that are dramatically different from the conventional microcomposites. Early in the 1990s, Usuki et al. synthesized clay/nylon6 nanocomposites ${ }^{1,2)}$. The nanocomposites exhibited various superior properties such as a high strength, high modulus, and high heat distortion temperature compared to pure nylon $6^{3)}$. Since then, many other clay/polymer nanocomposites have been produced, such as clay/ polypropylene nanocomposites ${ }^{4,5}$, clay/polystyrene nanocomposites ${ }^{6-8)}$, clay/poly(methyl methacrylate) nanocomposites ${ }^{8-10)}, \quad$ clay/poly(ethylene terephthalate) nanocomposites ${ }^{11,12)}$, clay/epoxy resin nanocomposites ${ }^{13)}$, clay/natural rubber nanocomposites ${ }^{14,15)}$, clay/styrene butadiene rubber nanocomposites ${ }^{16-18)}$, clay/nitrile rubber nanocomposites ${ }^{19)}$, etc. However, there are not many reports on the clay/thermoplastic elastomer (TPE) nanocomposites compared to the clay/plastic or clay/rubber nanocomposites.

TPEs are multi-functional polymeric materials that generally possess the processability of thermoplastics and the elasticity of vulcanized rubber. Polystyrene$b$-poly(ethylene-co-butylene)- $b$-polystyrene triblock copolymer (SEBS) is a commercially important TPE widely used in various applications, such as automotive parts, sporting goods, medical devices and food containers, because of its good balance of mechanical properties along with favorable processibility and recyclability. Enhancement of the performance properties of the TPE is required to address the demands of current engineering applications.

There are a few reports on the clay/SEBS 
nanocomposites. Krishnamoorti et al. prepared clay/SEBS nanocomposites by solution-mixing, and described the template effect of clay layers on microdomain structures in the nanocomposites ${ }^{20,21)}$. Hasegawa et al. prepared clay/SEBS nanocomposites by melt-blending, and demonstrated the ordered microdomain structures induced by the clay layers in the nanocomposites ${ }^{22)}$. Moreover, Jeon et al. obtained clay/SEBS nanocomposites containing the maleic anhydride modified SEBS as a compatibilizer by melt-blending, and found that the nanocomposites enhanced the mechanical properties ${ }^{23)}$.

Montmorillonite (Mt) is one of the widely used clays for clay/polymer nanocomposites. Mt has a layered structure with layers of around $1 \mathrm{~nm}$ thick and lateral dimensions of $100-1000 \mathrm{~nm}$. The individual layers consist of two silica tetrahedral sheets and one alumina octahedral sheet. The alumina sheet, in which part of the $\mathrm{Al}^{3+}$ is replaced by $\mathrm{Mg}^{2+}$, etc., generates negative charges in the layer. $\mathrm{Mt}$ includes exchangeable metal cations (e.g., $\mathrm{Na}^{+}$), which neutralize the net negative charges of the layer. These metal cations can be easily replaced by some organic cations. When $\mathrm{Mt}$ is used as a clay for preparing clay/polymer nanocomposites, Mt is usually modified with organic cations such as alkylammonium cations. Thus, the clay modification is of crucial importance for the preparation of the nanocomposites.

In this study, organically modified Mts (organo-Mts) with different amounts of distearyldimethylammonium (D18) cation were synthesized by an ion-exchange reaction, and then clay/SEBS intercalated composites were prepared by melt-blending. The effects of the clay modification on the microstructure and mechanical properties of these composites were mainly investigated.

\section{Experimental}

\section{Materials}

Mt (Kunipia-F) was obtained from Kunimine Ind. Co. The cation exchange capacity (CEC) of $\mathrm{Mt}$ is 115 meq./100 g. D18 chloride as a surface modifier was purchased from Tokyo Kasei Kogyo Co. SEBS (H1041) was supplied by Asahi Kasei Chemicals Co. The polystyrene block percentage is $30 \mathrm{wt} \%$. All materials were used as received.

\section{Syntheses of organically modified Mts}

Organo-Mts with different amounts of D18 were synthesized as follows. A $20.0 \mathrm{~g}$ sample of $\mathrm{Mt}$ was dispersed in $1000 \mathrm{~mL}$ of distilled water at $80^{\circ} \mathrm{C}$. Samples of $6.74 \mathrm{~g}$ (11.5 mmol, $50 \%$ of CEC), $9.44 \mathrm{~g}$ (16.1 mmol,
$70 \% \mathrm{CEC})$, and $13.5 \mathrm{~g}(23.0 \mathrm{mmol}, 100 \% \mathrm{CEC})$ of $\mathrm{D} 18$ chloride were separately dissolved in $1000 \mathrm{ml}$ of a $0.03 \mathrm{~N}$ $\mathrm{HCl}$ aqueous solution at $80^{\circ} \mathrm{C}$. These solutions were poured into the $\mathrm{Mt}$ dispersion and the mixture were vigorously stirred at $80^{\circ} \mathrm{C}$ for $30 \mathrm{~min}$. The resulting precipitates were filtered, washed five times with $1000 \mathrm{~mL}$ of hot water $\left(80^{\circ} \mathrm{C}\right)$, and freeze-dried to produce organoMts. The amounts of D18 in the organo-Mts were 50, 70 and $100 \% \mathrm{CEC}$, and the products were labeled D18Mt(50), D18Mt(70), and D18Mt(100), respectively. The apparent organic contents of $\operatorname{D18Mt}(50), \quad \operatorname{D18Mt}(70)$ and D18Mt(100), which were calculated from the weights before and after heating at $1000^{\circ} \mathrm{C}$ for $1 \mathrm{hr}$, were $32.3 \mathrm{wt} \%$, $38.1 \mathrm{wt} \%$ and $45.8 \mathrm{wt} \%$, respectively.

\section{Preparation of clay/SEBS composites}

The clay/SEBS composites were prepared by meltblending. Mixing was carried out using an internal mixer (Labo-Plastmil, Toyo Seiki Co.) for $5 \mathrm{~min}$ at $150^{\circ} \mathrm{C}$ and $150 \mathrm{rpm}$. The clays were Mt, D18Mt(50), D18Mt(70), and $\mathrm{D} 18 \mathrm{Mt}(100)$. The amounts of clay were 0, 2, 5, 7 and 10 wt $\%$. After melt-blending, the samples were hot-pressed at $180^{\circ} \mathrm{C}$ for $3 \mathrm{~min}$ at $10 \mathrm{MPa}$, followed by annealing at $120^{\circ} \mathrm{C}$ for 1 day under vacuum. The sheets were 1 or $6 \mathrm{~mm}$ thick.

\section{Characterization of clay/SEBS composites}

Field-emission scanning electron microscopy (FE-SEM) images were recorded using a Hitachi S-4500 at an acceleration voltage of $5 \mathrm{kV}$. The specimens were fractured in liquid nitrogen, and then the fractured surface was sputter-coated with gold. X-ray diffraction (XRD) measurements were performed using a Rigaku RINT2400V with $\mathrm{Cu} \mathrm{K}$ radiation at $40 \mathrm{kV}$ and $30 \mathrm{~mA}$. The basal spacing was calculated from the (001) peak position in the XRD pattern using Bragg's equation $(\mathrm{d}=\lambda / 2 \sin \theta)$. Dynamic mechanical analysis (DMA) was carried out using a TA instrument DMA2980 at a frequency of $1 \mathrm{~Hz}$ and heating rate of $5^{\circ} \mathrm{C} / \mathrm{min}$ from $-130^{\circ} \mathrm{C}$ to $200^{\circ} \mathrm{C}$ (or the temperature at which the sample lost its dimensional stability). The tensile properties were determined using a Shimadzu Autograph DCS-500 according to JIS (Japanese Industrial Standards) specifications. Both tensile specimens (JIS K 6251, a dumbbell shaped specimen of type 3) and tear specimens (JIS K 6252, an unnicked 90-degree angle specimen) were punched out from $1 \mathrm{~mm}$ thick compression-molded sheet samples. The crosshead speed was $100 \mathrm{~mm} / \mathrm{min}$. The hardnesses (Shore A) were measured using a hardness tester (JIS K 6253, a type A durometer). Hardness 
specimens were cut from $6 \mathrm{~mm}$ thick compression-molded sheet samples. These measurements were done at $23^{\circ} \mathrm{C}$ and $50 \% \mathrm{RH}$ in at least 5 replicates and the resulting data were averaged.

\section{Results and Discussion}

\section{Microstructure of clay/SEBS composites}

Figures $1(\mathrm{a}-\mathrm{d})$ are optical micrographs of the clay/SEBS composites with $5 \mathrm{wt} \%$ clay. The specimens are $1 \mathrm{~mm}$ thick sheets. The white particles in the figures are the agglomerated clay particles. As can be seen in Figure 1(a), the Mt/SEBS sheet was cloudy, and numerous agglomerated clay particles were observed in the SEBS matrix. The agglomerated particles became smaller, and the transparency of the sheet dramatically increased with an increase in the amount of D18 [Figures 1(a-d)]. When the amount of D18 reached 100\%CEC, the agglomerated clay particles completely disappeared in the SEBS matrix, and the sheet was optically transparent because of the high dispersion of the clay particles, as shown in Figure 1(d). It is apparent that the clay modification improved the dispersibility of the clay in the SEBS matrix.

Figures $2(\mathrm{a}-\mathrm{d})$ are FE-SEM images of the fracture surfaces of clay/SEBS composites with a $5 \mathrm{wt} \%$ clay content. The brighter plate-like particles in the figures are the clay particles, and the darker holes represent the

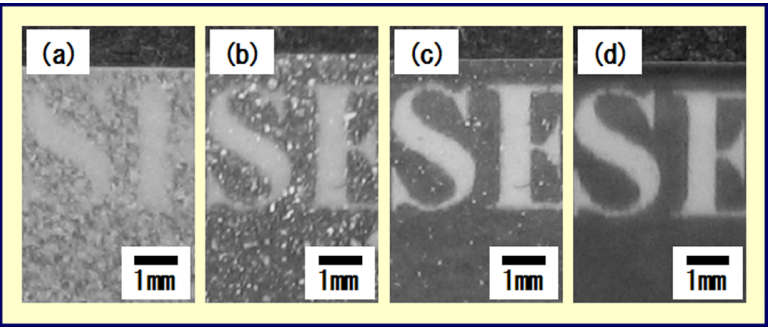

Figure 1. Optical micrographs of 5/95 clay/SEBS composites. (a): Mt/SEBS, (b): D18Mt(50)/SEBS, (c): D18Mt(70)/SEBS, (d): D18Mt(100)/SEBS.

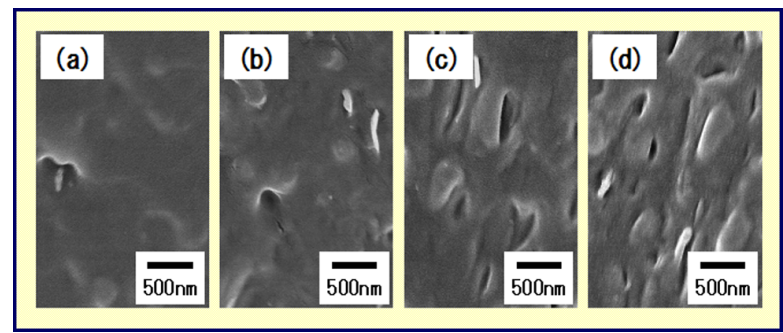

Figure 2. FE-SEM images of 5/95 clay/SEBS composites. (a): Mt/SEBS, (b): D18Mt(50)/SEBS, (c): D18Mt(70)/SEBS, (d): D18Mt(100)/SEBS. imprints of the clay particles. The clay particles are several tens of nm thick with lateral dimensions of 100-500 nm. This means that the clay particles consist of several tens of individual clay layers, and the clay layers are still stacked together. In Mt/SEBS [see Figure 2(a)], such fine particles are hardly seen, because clay is mostly agglomerated as the huge (visible) particles [see Figure 1(a)]. The number of clay particles increased as the amount of D18 increased [see Figures 2(a-d)]. In D18Mt(100)/SEBS [see Figure $2(d)]$, much finer particles of sub- $\mu \mathrm{m}$ are seen (no visible agglomerates) [see Figure 1(d)]. Mt has a hydrophilic surface, so it is incompatible with a nonpolar polymer such as SEBS. The surface modification of Mt with long-chain alkylammonium cations, such as the D18, is able to increase the hydrophobicity of the Mt surface. The change in the hydrophobicity would reduce the clay-clay interactions, and increase the compatibility between the clay and polymer. Therefore, the clay dispersion was improved by increasing the extent of the clay modification.

Figures 3 (A) and (B) show the XRD patterns of the clays and the clay/SEBS composites. Figure $3(\mathrm{~A})$ is the XRD patterns of the clays with different amounts of D18, in which the main peaks correspond to the (001) plane refractions of the clays. Mt exhibits a characteristic peak at $2 \theta=7.2^{\circ}$ in the XRD pattern, corresponding to the basal spacing of $1.2 \mathrm{~nm}$. In addition, D18Mt(50), D18Mt(70) and $\mathrm{D} 18 \mathrm{Mt}(100)$ have characteristic peaks at $2 \theta=3.6,3.4$ and $2.8^{\circ}$, respectively, which correspond to the basal spacings of $2.5,2.6$ and $3.1 \mathrm{~nm}$. The peaks of the organoMts were shifted to lower angles, compared to unmodified Mt. This clearly indicates that the D18 intercalated into the
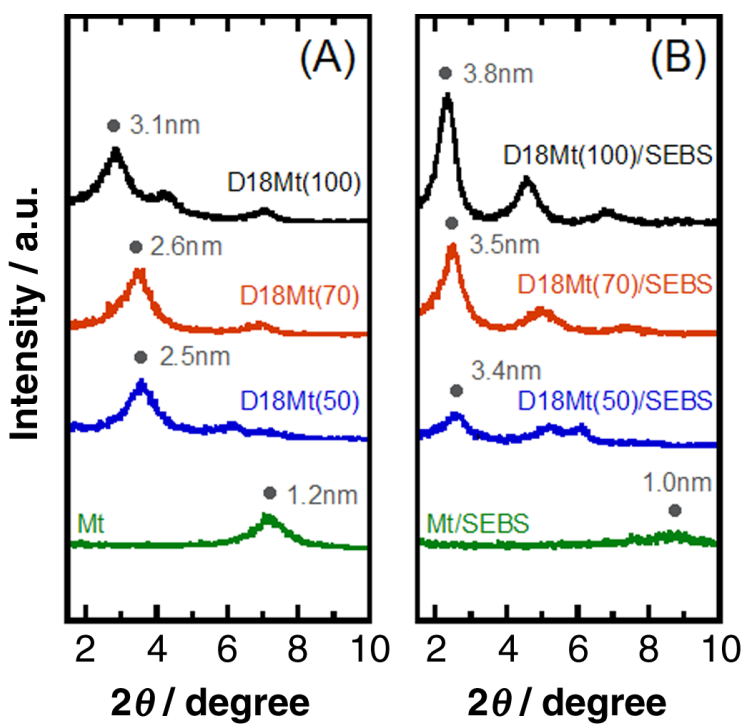

Figure 3. XRD patterns of (A) clays and (B) 5/95 clay/SEBS composites. 
clay interlayers, and expanded the basal spacings. According to Lagaly ${ }^{24)}$, the alkylammonium cations adopt various molecular arrangements in the clay galleries depending on the packing density of the ion-exchanged cations. As the packing density increases, the alkyl chains adopt more extended conformations. The basal spacing of each organo-Mt is based on the interlayer structure.

Figure 3(B) is the XRD patterns of the clay/SEBS composites with $5 \mathrm{wt} \%$ clay. Mt/SEBS has a characteristic peak at $2 \theta$ of $8.8^{\circ}$, corresponding to the basal spacing of $1.0 \mathrm{~nm}$. Through melt-blending, the basal spacing of Mt/SEBS decreased when compared to the original Mt, due to the loss of the interlayer water in Mt. This implies that no insertion of the SEBS chains into the interlayers of unmodified Mt occurred. In contrast, D18Mt(50)/SEBS, D18Mt(70)/SEBS and D18Mt(100)/SEBS have characteristic peaks at $2 \theta=2.6,2.5$ and $2.3^{\circ}$, respectively, which correspond to the basal spacings of $3.4,3.5$ and 3.8 $\mathrm{nm}$. After melt-blending, the basal spacings of the organoMt/SEBSs were $0.7-0.9 \mathrm{~nm}$ longer than those of the original organo-Mts. These suggest that the SEBS chains were inserted into the interlayers of organo-Mts, and further imply the formation of intercalated composites. However, no exfoliation was observed even in the organoMt/SEBSs. This may be caused by only a weak interaction between the organo-Mt and SEBS without any functional groups.

\section{Dynamic mechanical properties of clay/SEBS composites}

Figure 4 displays the dynamic storage modulus $\left(E^{\prime}\right)$ and loss tangent $(\tan \delta)$ as a function of the temperature for pure SEBS and clay/SEBS composites. The $E^{\prime}$ s of pure SEBS and clay/SEBS composites decreased with the



Figure 4. DMA curves of 10/90 clay/SEBS composites. increasing temperature with a drop at $-37^{\circ} \mathrm{C}$, corresponding to the glass-rubber transition of the poly(ethylene-butylene) (PEB) block matrix, and another drop at higher temperature, coresponding to the glass transition of the polystyrene (PS) block domain. In the rubbery plateau region, the $E^{\prime} \mathrm{s}$ of the organo-Mt/SEBS composites were higher than that of pure SEBS. Whereas, the $E^{\prime}$ of Mt/SEBS was less than that of pure SEBS. As mentioned above, the organo-Mts have a better dispersibility in comparison to the unmodified Mt. The reinforcement effect may be caused by the high dispersion of the organo-Mts in the SEBS. Aside from this, in the flow region, the $E^{\prime}$ s of the organo-Mt/SEBS composites are much higher than that of pure SEBS. To explain the behavior in the flow region, more research needs to be done.

In the $\tan \delta$ curves, two peaks were observed that were related to the main relaxation processes. The temperature of the main relaxation is considered to be the glass transition temperature $\left(T_{g}\right)$. As shown in Figure 4 , the $T_{g} \mathrm{~s}$ of the PEB block matrix and the PS block domains of pure SEBS were $-37^{\circ} \mathrm{C}$ and $101^{\circ} \mathrm{C}$, respectively. For organoMt/SEBS composites, the $T_{g}$ of the PEB matrix was essentially unchanged, however, the $T_{g}$ of the PS domains slightly shifted to a lower temperature with the increasing amount of D18. For example, the $T_{g}$ of the PS domains of $\mathrm{D} 18 \mathrm{Mt}(100) / \mathrm{SEBS}$ was $97^{\circ} \mathrm{C}$, which was less than that of pure SEBS. That means that the surface modification of Mt with D18 did not affect the PEB matrix, but affected the PS domains. According to both Krishnamoorti et al. ${ }^{20,21)}$ and Hasegawa et $a .^{22)}$, the PS segments of SEBS are preferentially adsorbed on the surface of the organo-Mt. Therefore, this behavior suggests that the D18 chains on the clay surface may play a role of plasticizer for PS segments. On the contrary, the two $T_{g} \mathrm{~s}$ of Mt/SEBS were the same as those of pure SEBS. This means that the addition of the unmodified Mt did not basically affect either the PEB matrix or the PS domains of SEBS.

\section{Tensile properties of clay/SEBS composites}

The tensile moduli at the $100 \%$ and $300 \%$ elongations $\left(M_{100}\right.$ and $\left.M_{300}\right)$, tensile strength $\left(T_{B}\right)$, elongation at break $\left(E_{B}\right)$ and tear strength $\left(T_{R}\right)$ of the clay/SEBS composites were measured. Figures 5, 6 and 7 show the effect of the clay content on the tensile properties of clay/SEBS composites. When Mt and SEBS were mixed, the $M_{100}$ and $M_{300}$ slightly increased with the increasing clay content, as shown in Figure 5. Whereas, in the case of the organoMt/SEBS composites, the $M_{100}$ and $M_{300}$ rapidly increased with the increasing clay content. The reinforcement effect 


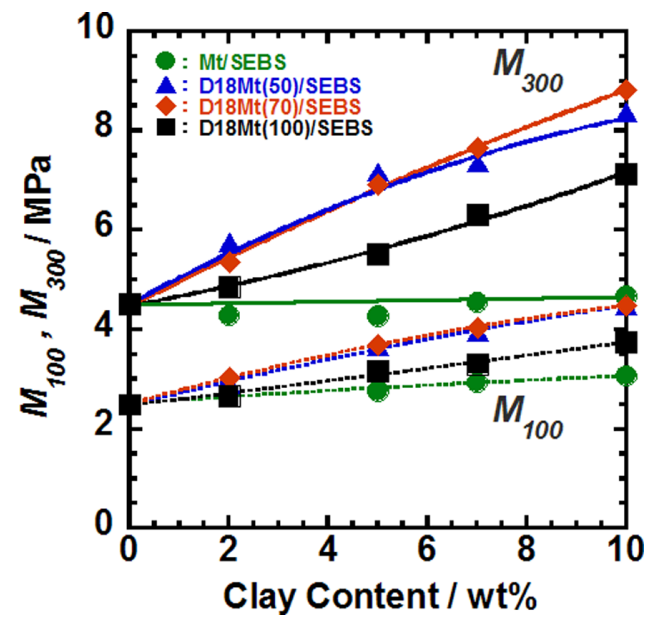

Figure 5. Effect of clay content on the tensile moduli of clay/SEBS composite, recorded at $100 \%$ of elongation and $300 \%$ of elongation.

of the clay was more significant in the organo-Mt/SEBS composites.

As seen in Figure 6, the $T_{B}$ of Mt/SEBS decreased when the clay content increased. The $T_{B} \mathrm{~s}$ of $\mathrm{D} 18 \mathrm{Mt}(50) / \mathrm{SEBS}$ and $\mathrm{D} 18 \mathrm{Mt}(70) / \mathrm{SEBS}$ were almost constant in the clay content range of $0-5 \mathrm{wt} \%$, but decreased for the clay content higher than $5 \mathrm{wt} \%$. These decreases are probably due to some agglomerations of the clay particles. Whereas, the $T_{B}$ of $\mathrm{D} 18 \mathrm{Mt}(100) / \mathrm{SEBS}$ was maintained virtually constant with the clay content in the range of $0-10 \mathrm{wt} \%$. Similarly, the $E_{B} \mathrm{~S}$ of $\mathrm{Mt} / \mathrm{SEBS}, \mathrm{D} 18 \mathrm{Mt}(50) / \mathrm{SEBS}$ and $\mathrm{D} 18 \mathrm{Mt}(70) / \mathrm{SEBS}$ decreased as the clay content increased. However, in D18Mt(100)/SEBS, the $E_{B}$ basically remained constant in the clay content range of $0-10 \mathrm{wt} \%$. Additionally, the $T_{R}$ of Mt/SEBS slightly decreased, however, those of the organo-Mt/SEBS composites increased with the increasing clay content, as shown in Figure 7.

The mechanical properties of the clay/SEBS composites with $10 \mathrm{wt} \%$ of clay and pure SEBS are summarized in Table 1. The effect of the clay modification on the mechanical properties of the clay/SEBS composites was investigated. The $M_{100}$ and $M_{300}$ of the clay/SEBS dramatically increased with the increasing amount of D18 from 0 to $70 \%$ CEC. For example, the $M_{300}$ of Mt/SEBS was 4.67 MPa, which was close to that of pure SEBS (4.51 $\mathrm{MPa})$. When the amount of D18 reached $70 \% \mathrm{CEC}$, the $M_{300}$ increased 2.0-fold (8.82 MPa) over that of pure SEBS. The reinforcement effect of clay became more prominent with the increasing amount of D18, because the clay modification improved the clay dispersion in the SEBS matrix. As already mentioned, the PS segments of SEBS are preferentially adsorbed on the surface of the

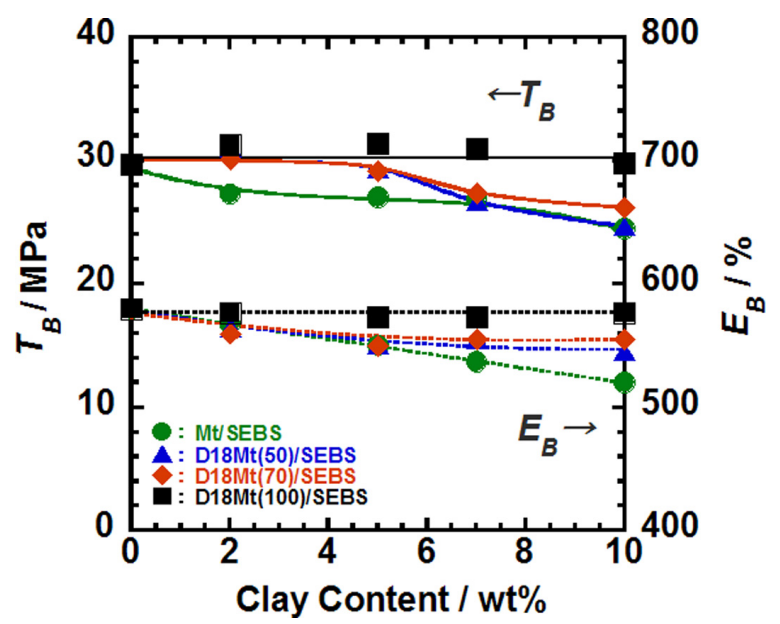

Figure 6. Effect of clay content on the tensile strength and elongation at break of clay/SEBS composite.

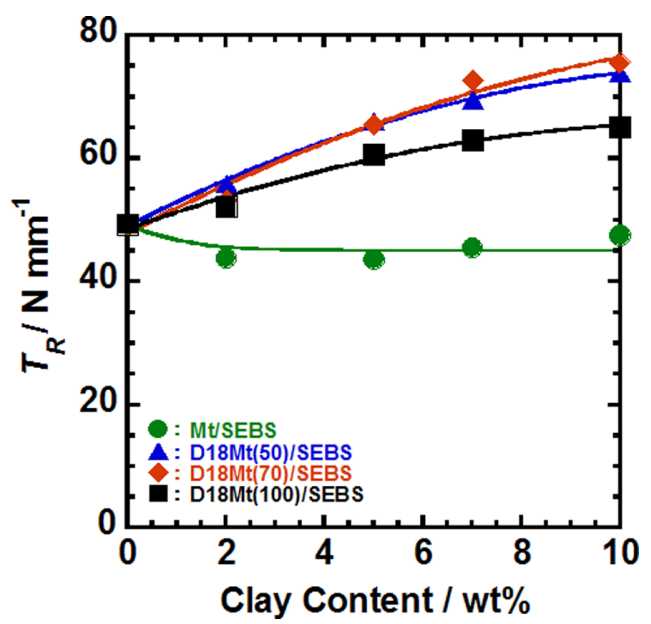

Figure 7. Effect of clay content on the tear strength of clay/SEBS composite.

organo- $\mathrm{Mt}^{20-22)}$. Therefore, the reinforcement effect may be caused by the interaction of the organo-Mt particles and the SBES matrix, which is provably the hydrophobic interaction between the D18 alkyl chains of organo-Mt and the PS segments of SEBS. However, it is noteworthy that the $M_{100}$ and $M_{300}$ of the clay/SEBS decreased for the amount of D18 higher than $70 \%$ CEC. The $M_{300}$ of $\mathrm{D} 18 \mathrm{Mt}(100) / \mathrm{SEBS}$ was $7.12 \mathrm{MPa}$, which was higher than that of pure SEBS, but was less than that of D18Mt(70)/SEBS. D18Mt(100) has the higher organic content (45.8 wt\%) compared to $\mathrm{D} 18 \mathrm{Mt}(70)$ (38.1 wt\%). The decrease with the increasing amount of D18 from 70 to $100 \%$ CEC may be attributable to the slip in the interface between $\mathrm{D} 18 \mathrm{Mt}(100)$ particles and SEBS matrix. That is, an excess of D18 alkyl chains on the clay surface may weaken the interaction between the organo-Mt particles 
Table 1. Mechanical properties of $10 / 90$ clay/SEBS composites and pure SEBS

\begin{tabular}{lcccccc}
\hline Clay/SEBS & $\mathrm{M}_{100}(\mathrm{MPa})$ & $\mathrm{M}_{300}(\mathrm{MPa})$ & $T_{B}(\mathrm{MPa})$ & $E_{B}(\%)$ & $T_{R}(\mathrm{MPa})$ & $H_{S}($ Shore A) \\
\hline $\mathrm{Mt} / \mathrm{SEBS}$ & 3.07 & 4.67 & 24.5 & 520 & 47.5 & 81 \\
D18Mt(50)/SEBS & 4.49 & 8.37 & 24.7 & 545 & 73.9 & 83 \\
D18Mt(70)/SEBS & 4.49 & 8.82 & 26.2 & 555 & 75.6 & 83 \\
D18Mt(100)/SEBS & 3.75 & 7.12 & 29.8 & 577 & 65.1 & 83 \\
SEBS & 2.49 & 4.51 & 29.7 & 580 & 49.3 & 80
\end{tabular}

and the SEBS matrix. However, a further investigation is required to clearly explain this behavior. The $T_{B}$ and $E_{B}$ of the clay/SEBS increased, as the amount of D18 increased. The $T_{B}$ and $E_{B}$ of $\mathrm{Mt} / \mathrm{SEBS}(24.5 \mathrm{MPa}, 520 \%$ ) were remarkably less than those of pure SEBS $(29.7 \mathrm{MPa}$, $580 \%)$. On the other hand, the $T_{B}$ and $E_{B}$ of D18Mt(100)/SEBS (29.8 MPa, 577\%) were almost equal to those of pure SEBS. The $T_{B}$ and $E_{B}$ of the clay/SEBS was improved by the surface modification of Mt with D18. This is mainly due to the high dispersion of organo-Mt. In addition, the $T_{R}$ of the clay/SEBS rapidly increased with the amount of D18 in the range of $0-70 \%$ CEC, and decreased with a further change in the amount of D18. The $T_{R}$ of Mt/SEBS was $47.5 \mathrm{MPa}$, which was slightly less than that of pure SEBS $(49.3 \mathrm{MPa})$. In contrast, the $T_{R}$ of $\mathrm{D} 18 \mathrm{Mt}(70) / \mathrm{SEBS}$ was $75.6 \mathrm{MPa}$, which was 1.5 times higher than that of pure SEBS. A similar kind of behavior can be observed for the hardness $\left(H_{S}\right)$ of the clay/SEBS. These results mean that the extent of the clay modification significantly affects the mechanical properties of the clay/SEBS composites. When the amount of D18 was $100 \%$ CEC, the composite displayed an improved $M_{100}$, $M_{300}, T_{R}$ and $H_{S}$ compared to pure SEBS, without sacrificing the $T_{B}$ and $E_{B}$.

\section{Conclusions}

We synthesized the organo-Mts with different amounts of D18 via the cation-exchange reaction between Mt and D18. And, we prepared the clay/SEBS intercalated composites using the organo-Mts through melt-blending.

The clay modification effectively improved the clay dispersion in the SEBS matrix and the mechanical properties of the clay/SEBS composites. In particular, D18Mt(100)/SEBS displayed an improved $M_{100}, M_{300}, T_{R}$ and $H_{S}$ compared to pure SEBS, without sacrificing the $T_{B}$ and $E_{B}$. We found that the extent of clay modification, that is, the amount of D18 in the organo-Mt was an important factor for determining the microstructure and mechanical properties of the clay/SEBS composites.

\section{References}

1) Usuki A., Kojima Y., Kawasumi M., Okada A., Fukushima Y., Kurauchi T., Kamigaito O.: J. Mater. Res., 8, 1179 (1993).

2) Usuki A., Kawasumi M., Kojima Y., Okada A., Kurauchi T., Kamigaito O.: J. Mater. Res., 8, 1174 (1993).

3) Kojima Y., Usuki A., Kawasumi M., Okada A., Fukushima Y., Kurauchi T., Kamigaito O.: J. Mater. Res., 8, 1185 (1993).

4) Kawasumi M., Hasegawa N., Kato M., Usuki A., Okada A.: Macromolecules, 30, 6333 (1997).

5) Hasegawa N., Kawasumi M., Kato M., Usuki A., Okada A.: J. Appl. Polym. Sci., 67, 87 (1998).

6) Vaia R., Ishii H., Giannelis E.: Chem. Mater, 5, 1694 (1993).

7) Hasegawa N., Okamoto H., Kawasumi M., Usuki A.: J. Appl. Polym. Sci., 74, 3359 (1999).

8) Zeng C., Lee L. J.: Macromolecules, 34, 4098 (2001).

9) Lee D. C., Jiang L. W.: J. Appl. Polym. Sci., 61, 1117 (1996).

10) Huang X., Brittain W. J.: Macromolecules, 34, 3255 (2001).

11) Ke Y., Long C., Qi Z.: J. Appl. Polym. Sci., 71, 1139 (1999).

12) Ou C. F., Ho M. T., Lin J. R.: J. Appl. Polym. Sci., 91, 140 (2004).

13) Lin J. J., Cheng I. J., Chu C. C.: Polym. J., 35, 411 (2003),

14) Vu Y. T., Mark J. E., Pham L. H., Engelhardt M.: J. Appl. Polym. Sci., 82, 1391 (2001).

15) Manchado M. L., Herrero B., Arroyo M.: Polym. Int., 52, 1070 (2003).

16) Zhang L., Wang Y., Wang Y., Sui Y., Yu D.: J. Appl. Polym. Sci., 78, 1873 (2000).

17) Wang Y., Zhang L., Tang C., Yu D.: J. Appl. Polym. Sci., 78, 1879 (2000).

18) Ma J., Xiang P., Mai Y. W., Zhang L. Q.: Macromol. Rapid Commun., 25, 1692 (2004).

19) Kim J. T., Oh T. S., Lee D. H.: Polym. Int., 52, 1058 (2003).

20) Silva A. S., Mitchell C. A., Tse M. F., Wang H. C., Krishnamoorti R.: J. Chem. Phys., 115, 7166 (2001).

21) Krishnamoorti R., Silva A. S., Mitchell C. A.: J. Chem. Phys., 115, 7175 (2001).

22) Hasegawa N., Usuki A.: Polym. Bull., 51, 77 (2003).

23) Chang Y. W., Shin J. Y., Ryu S. H.: Polym. Int., 53, 1047 (2004).

24) Lagaly G.: Solid State Ionics, 22, 43 (1986). 